\title{
Management of Pregnancy in Women of Advanced Maternal Age: Improving Outcomes for Mother and Baby
}

\author{
Itamar Glick' \\ Ela Kadish iD ${ }^{2}$ \\ Misgav Rottenstreich (D) ${ }^{1,3}$ \\ 'Department of Obstetrics \& \\ Gynecology, Shaare Zedek Medical \\ Center and Faculty of Medicine, Hebrew \\ University of Jerusalem, Jerusalem, Israel; \\ ${ }^{2}$ Faculty of Medicine, Hebrew University \\ of Jerusalem, Jerusalem, Israel; \\ ${ }^{3}$ Department of Nursing, Jerusalem \\ College of Technology, Jerusalem, Israel
}

\begin{abstract}
Pregnancy at advanced maternal age (age $>35$ years old) is considered a risk factor for adverse maternal and perinatal outcomes. Yet, pregnancies of advanced maternal age have become more prevalent over the last few decades. Possible maternal complications of pregnancy at age 35 or older include increased risk of spontaneous miscarriage, preterm labor, gestational diabetes mellitus, pre-eclampsia, stillbirth, chromosomal abnormalities, and cesarean delivery. Possible adverse fetal outcomes include infants small for gestational age and intrauterine growth restrictions, low Apgar score, admission to neonatal intensive care units, and an autism spectrum disorder. This paper aims to present an up-to-date review of the literature, summarizing the most current studies and implications for the management of pregnancy of advanced maternal age.
\end{abstract}

Keywords: advanced maternal age, adverse maternal outcome, adverse perinatal outcome

\section{Introduction}

Over the last several decades, developed countries have witnessed an increase in the average age of conception and delivery for women. ${ }^{1}$ A Centers for Disease Control and Prevention (CDC) report documented an increasing birth rate among advanced maternal age (AMA, maternal age $>35$ years) women over the past 3 decades in the United States. Analysis of the data from the last decade showed an increase in the birth rate for women aged 35-39 years from 45.9 per 1000 women in 2010, to 52.7 in 2019 . $^{2,3}$ Similarly, there was an increase in the birth rate for women aged 40-44 years from 10.2 to 12 per $1000 .^{2,3}$ This trend can be explained by women choosing to pursue careers and financial security, leading them to postpone childbearing age. ${ }^{4-6}$ Additionally, developments in advanced reproductive technology (ART) have extended the reproductive window, with a corresponding increase incidence of AMA.,

Although there is no standardized definition of AMA, one common definition is of maternal age above $35.8,9$ Beyond that, maternal age above 40 is considered very advanced maternal age (VAMA), and above 45, very late maternal agelextremely advanced maternal age (EAMA). ${ }^{10,11}$

AMA is considered a risk factor for adverse maternal and fetal outcomes. Some maternal complications include gestational diabetes mellitus (GDM), gestational hypertension (HTN), and cesarean delivery. Detrimental perinatal outcomes include higher rates of chromosomal abnormalities, miscarriage, pre-term labor, neonatal intensive care unit (NICU) admissions, and stillbirth. ${ }^{8,9}$
Correspondence: Misgav Rottenstreich Department of Obstetrics and

Gynecology, 12 Bayit Shaare Zedek Medical Center, Jerusalem, 91031, Israel Tel +972 2- 655-5562

Fax +972 2-666-6053

Email misgavr@gmail.com 
The purpose of this review is to provide an up-to-date overview of possible maternal and fetal complications during pregnancy in AMA, as well as current recommendations for examinations during pregnancy.

\section{Materials and Methods}

Five major search engines, namely MEDLINE, PubMed, Google Scholar, and Cochrane Library, were searched for articles published before March 2020 that matched any combination of the following keywords: [advanced maternal age] OR [advancing maternal age] OR [older maternal age] OR [older women] OR [older mothers] OR [maternal age] AND [pregnancy outcome] OR [maternal outcome] OR [neonatal outcomes] OR [pregnancy complications]. Only scientific papers in English were included. We studied the references and conducted a citation search. Two co-authors (IG and MR) independently selected, evaluated, and extracted data. The criteria for inclusion of the literature source were limited to the presence of information regarding the pathogenesis and outcome of pregnancyrelated complications including original studies and structured reviews. The criterion for the exclusion of the article was based on study design (case reports, unstructured literature reviews, pharmaceutical studies were excluded), availability of the study (subscription access, open access), date of publication (later than 2000 studies included, and historically important studies) and relevance.

The primary evaluation indicated that our search strategy had identified a large number of irrelevant studies. Criteria to eliminate studies that did not address our research question were developed throughout article processing to narrow the ongoing search. These criteria identified a total of 841 articles for review. Following screening the titles of the studies, 358 articles were excluded for reasons of scope and/or not meeting the inclusion and exclusion criteria of the review. After screening the abstract of the studies, a total of 124 full-text articles were retrieved and analyzed for eligibility; of these, 77 articles were excluded because of irrelevant or repetitive conclusions to the study purpose. Finally, 47 articles were included for the qualitative analysis in the current review.

\section{Results}

\section{Maternal Risks}

\section{Ectopic Pregnancies}

Several studies report higher ectopic pregnancy rates among women of AMA. In a study from Norway, women over 35 years old had a risk of ectopic pregnancy eight times greater than women between the ages of 15-19 years. ${ }^{12}$ Nybo Andersen et al reported similar results. ${ }^{13}$ This may be explained by the accumulation of ectopic pregnancy risk factors over time, such as multiple sexual partners, pelvic infection, and tubal pathology. ${ }^{14}$

\section{Hydatidiform Mole}

Molar pregnancies (MP) are divided into two main subgroups; complete mole $(\mathrm{CM})$ which is characterized by 46 xx karyotypes (haploid sperm and empty ovum fertilization), and partial mole (PM) with a triploid karyotype (fertilization of 2 sperm and an ovum).

MP can result in a trophoblastic tumor, which required chemotherapy.

The incidence of MP as a function of age demonstrates a U-shaped curve. In a population database study from England and Wales, the incidence of MP declined from age 13 to 34 from a range of 1:208 to $1: 654$. Whereas at age 35 onward, the incidence began to rise again, with an incidence of 1:423 at 40 years and 1:101 at 45 years old women. Looking at CM vs PM, at PM there is a small increase with maternal age, with risks of 1:903, 1:650, and 1:286 at ages of 35,40 , and 45 , relatively. On the other hand, with CM, the risk began to rise at age 40 , but with a rapid increase of incidence; from 19-40 years old the risk is above $1: 1248$ pregnancies, at 41,45 , and 50 years old, the incidence is 1:993, 1:157 and 1:8 relatively. The risk for chemotherapy also increases with AMA, at AMA the prevalence was $17.9 \%$, and at VAMA and EAMA it was above $20 \%{ }^{15}$

Another retrospective study from the US also demonstrated an increased risk of CM at VAMA of 1.9 times (95\% CI 1.2-3.1; p 0.006), but without a significant increase in PM with maternal age. ${ }^{16}$

The difference in the increase of incidence by age between CM and PM can be due to the hypothesis that with older maternal age, there is a greater chance of fertilizing an abnormal oocyte.

\section{Multiple Gestation}

Advanced maternal age is a known risk factor for multiple gestations in naturally conceived pregnancies that result from multiple ovulations, associated with higher maternal follicle-stimulating hormone (FSH) levels and following higher rates of ART used in older women. However, the outcome of multiple pregnancies in AMA women is as good as the outcome in younger women. ${ }^{17}$ 


\section{Gestational and Pre-Gestational Diabetes Mellitus}

The incidence of insulin resistance and diabetes mellitus increases with age, and it is thus not surprising that the incidence of GDM also increases at AMA.

A retrospective study by Khalil and coworkers describe an increased GDM incidence of 1.62 (95\% CI 1.43-1.83, $\mathrm{P}<0.001)$ and $2.1(95 \% \mathrm{CI} 1.74-2.55, \mathrm{P}<0.001)$ at AMA and VAMA, respectively, compared to women under the age of 35 years. The risk of GDM remains higher in older ages, even after adjusting for confounding variables such as ethnicity and obesity. ${ }^{18,19}$

Reduction in insulin sensitivity and deterioration of pancreatic B-cell function seems to be the main reasons for the increased incidence of GDM with age.

Moreover, environmental factors can affect the incidence of GDM at AMA. Dong et al demonstrated in a prospective study that elevated pre-pregnancy body mass index (BMI) independently increases the risk for GDM, particularly in AMA, when compared to a control group of maternal age between 20 and 35 years. ${ }^{20}$ Pregestational diabetes, which is also more common among women at AMA, is associated with increased risks of fetal malformations, perinatal morbidity (mainly macrosomia and its sequelae), and mortality. ${ }^{21}$

\section{Hypertension Disorders in Pregnancy and Pre-Eclampsia}

Advanced age is a known risk factor for HTN due to endothelial damage which increases with age. It is thus reasonable to expect higher rates of chronic HTN, as well as an increased incidence of gestational HTN and preeclampsia (PET) among women of AMA. A retrospective study by Nieto et al comparing AMA, VAMA \& EAMA to a control group of women under 30 years of age, using univariate analysis, revealed an increased risk for PET only at EAMA (OR 3.32, 95\% CI 1.78-6.21). However, after using a multivariable logistic regression for confounding factors (obesity, use of ART, smoking, chronic HTN, and parity) there was no significant association between age and PET. ${ }^{11}$

On the other hand, a systematic review from 2016 of 92 cohort studies, with more than 1000 participants in each study, demonstrated an increased relative risk of $1.2(95 \%$ CI 1.1-1.3) and $1.5(95 \%$ CI $1.2-2.0)$ at AMA and VAMA, respectively. ${ }^{22}$

A recent study compared women with PET at an AMA with women with PET between the ages 20 to 34 years old, in terms of maternal and perinatal outcomes. They found that for women of an AMA, PET is an independent risk factor for postpartum hemorrhage ( $\mathrm{PPH})(\mathrm{OR}=3.89$, 95\% CI 1.16-13.03). Moreover, in the AMA group, the incidence of $\mathrm{CD}$ was significantly higher $(53.5 \%$ vs $28.6 \%, \mathrm{p}<0.005){ }^{23}$

Needless to say, PET has long-term implications on the cardiovascular health of older women. PET is an independent risk factor for future heart failure, coronary heart disease, and stroke. ${ }^{24}$

Several possible mechanisms have been proposed for the association between AMA and the increased prevalence of PET, among them; decreased maternal hemodynamic adaptation during pregnancy, loss of compliance of the uterine blood vessels, and comorbid disease. ${ }^{25,26}$

The use of low-dose aspirin as a prophylaxis treatment to reduce PET incidence in AMA women ${ }^{27}$ has been suggested by numerous authors.

\section{Cesarean Delivery}

The risk for $\mathrm{CD}$ increases dramatically with age. A retrospective cohort study from Washington state demonstrated that the primary $\mathrm{CD}$ incidence for 25 to 34 years old (referent group) was $20.0 \%$; the incidence for the AMA group was $25.9 \%$, with a relative risk $(\mathrm{RR})=1.25$ (95\% CI 1.20 to 1.29 ); the incidence for the VAMA was $30.9 \%, \mathrm{RR}=1.45(95 \%$ CI 1.40 to 1.50$)$; the EAMA incidence was $35.7 \%, \mathrm{RR}=1.59$ (95\% CI 1.45 to 1.75 ); and, in women above the age of 50 years, the CD incidence was $60.7 \%, \mathrm{RR}=2.44(95 \%$ CI 1.95 to 3.05$)$. Although CD rates were higher at primiparous compared to multiparous, this trend was the same for both subgroups. ${ }^{28}$ It is important to highlight that there was no trend of increased operative vaginal delivery associated with increased age.

There are several potential etiologies for this trend. Treacy et al and Waldenstrom et al found AMA to be a risk factor for labor dystocia and therefore higher rates of $\mathrm{CD}$ in this parturient group. ${ }^{29,30}$

Rydahi and her colleagues also demonstrated an increased risk for CD at AMA (aOR 2.18, 95\% CI 2.112.26) and VAMA (aOR 3.64, 95\% CI 3.41-3.90) as compared to women aged $<30$, suggesting that the increasing rate of $\mathrm{CD}$ was due to maternal preferences and lower treatment threshold for intervention. ${ }^{31}$ Apparently, all three mechanisms proposed are correct, so the increased rate of $\mathrm{CD}$ can be explained by each one of them, and by all of them together. 


\section{Maternal Mortality and Other IIInesses}

The leading etiologies for maternal mortality include hemorrhage, infection, and cardiovascular pathologies. An updated review on AMA presented an increasing maternal mortality rate (MMR) of 7.7 times for VAMA compared to women aged $<25 .{ }^{32}$ In the same way, another review on AMA demonstrated an increase in MMR when comparing pregnant women under age 35 with AMA women (10.8 vs 38 deaths per 100,000 births). This relatively high rate can be explained by comorbidities and other coexisting diseases at AMA. ${ }^{14}$

Likewise, the risk for other adverse illnesses increases with older maternal age. Amniotic fluid embolism and obstetric shock are eight-fold and three-fold higher at VAMA comparing to 25-29 years old women. On the contrary, women who gave birth after age 33 had increasing odds (two times) of living to age 95 comparing women with their last birth before age $30 .^{32}$

\section{Adverse Fetus Outcomes Spontaneous Miscarriage}

The incidence of miscarriage increases with maternal age, with incidences for AMA, VAMA, and EAMA at approximately $25 \%, 50 \%$, and $90 \%$, respectively. ${ }^{32,33}$ Leader and her colleagues, in a recent systematic review regarding risks of EAMA, demonstrated that the risk of fetal loss is about 2.6 (95\% CI 1.47-4.62) as compared to pregnancies before the age of $45 .{ }^{34}$

Chromosomal abnormalities are thought to be the leading cause of spontaneous miscarriage in the first trimester. ${ }^{35,36}$ A recent study from China examined the relationship between chromosomal abnormalities, AMA, and spontaneous miscarriage in 497 pregnancies, and found that the rate of fetal chromosomal abnormalities in spontaneous miscarriages at VAMA is significantly higher as compared to younger women $(60.6 \%$ vs $33.5 \%$ in women aged 30-34). The most common chromosomal aneuploidy was trisomy 22 , followed by trisomy 16 and trisomy $21 .^{37}$

It has been proposed that errors at meiosis 1 and 2, mitochondrial dysfunction, and other molecular mechanisms are responsible for the increased chromosomal aneuploidy related to AMA. It is interesting to note that there may also be nutritional factors as well as lifestyle-related factors that can affect oocyte quality (BMI, preconception folic acid supplementation use, chronic administration of anti-oxidant supplementation, etc.). This field of research requires further research to draw clear conclusions and recommendations, which are currently lacking. ${ }^{38}$

The benefit of preimplantation genetic testing for aneuploidy (PGT-A) in reducing miscarriage rates has been proven in several studies. ${ }^{39,40}$ Although there were no differences in the cumulative delivery rates, more research is needed concerning this technique. ${ }^{41}$

\section{Chromosomal Abnormalities and Congenital Anomalies}

As noted above, chromosomal abnormalities have an increased prevalence among fetuses of AMA women. Frederiksen et al found chromosomal abnormalities at a rate of $0.56 \%, 1.32 \%$, and $3.83 \%$ in parturients between the ages of 20-34, AMA and VAMA, respectively (Pearson $\mathrm{x}^{2}<0.001$ ). Looking at congenital abnormalities, they found no significant difference between the three maternal groups. ${ }^{8}$ These findings are consistent with other studies. $^{27}$

A Korean study, which evaluates the association between AMA and chromosomal abnormalities, found a close correlation between trisomy 18 and 21 and maternal age. Above the age of 35, every increase in a year is associated with an increased risk of trisomy 18 and 21 by 1.182 and 1.177 times, respectively. Concerning all aneuploidies, above 35 years old, the odds ratio also increased by 1.160 times, with increasing age. ${ }^{42}$

Conflicting results concerning AMA and the risk of (Turner Syndrome) TS have been reported. Carothers et al observed no association between maternal age and $45, \mathrm{X}$ monosomics. ${ }^{43}$ On the other hand, in a large study on 88,965 second trimester amniocenteses, an increased incidence of $45, \mathrm{X} / 46, \mathrm{XX}$ mosaic fetuses was seen in women $\geq 35$ years of age. ${ }^{44}$ In a similar way, Hagman et al found higher rates of VAMA but not AMA among women who gave birth to neonates with TS $(0.05 \%$ in VAMA women vs $0.03 \%$ in AMA and women aged $<35$ years old, aOR 1.83, 95\% CI 1.09-3.08). ${ }^{45}$

Fortunately, there are very effective screening tests to identify chromosomal abnormalities during pregnancy. Although there is no single agreed-upon guideline for optimal screening method, a detailed first-trimester ultrasound, along with the first trimester combined test or circulating free DNA (cfDNA) testing is highly recommended. ${ }^{46}$ While invasive diagnostic procedures in AMA women with normal screening tests may not be indicated, amniocentesis seems to be the preferred test, especially when funded by health authorities. ${ }^{47-49}$ Due to 
the relatively high level of safety in amniocentesis with a miscarriage rate of $0.3 \%$ (95\% CI $0.11-0.49 \%)$, AMA women who prefer diagnostic tests can be reassured about the procedure's safety. ${ }^{50}$

An interesting retrospective study about the prevalence of congenital anomalies in AMA pregnancies with euploid fetuses found AMA to be a protective factor with regard to congenital anomalies (aOR 0.59, 95\% CI 0.52-0.66). This phenomenon can be explained by the "all or none" theory, which assumes that at advanced oocyte age, anatomically normal fetuses have a higher survival rate. ${ }^{51}$

On the contrary, a review from 2020 on the pregnancy outcome at AMA reported an increased risk of two times for cardiac defects, esophageal atresia, and craniosynostosis at VAMA women compared to the reference group of women $25-29$ years old. ${ }^{14}$

\section{Preterm Delivery}

Waldenstrom et al, in a large retrospective study of more than $2 * 10^{\wedge 6}$ pregnancies, demonstrated that AMA and VAMA increased the risks of both spontaneous and medically indicated preterm birth, irrespective of parity: in very preterm birth (22-31 weeks of gestation) adjusted ORs in first, second, and third deliveries ranged from 1.59 to 1.70 at 35-39 years, and from 1.97 to 2.40 at $\geq 40$ years. In moderate preterm births (32-36 weeks of gestation), agerelated associations were weaker but were statistically significant from 35 to 39 years in all parity groups. ${ }^{52}$

Similarly, a contemporary large retrospective study from Canada found pregnancy at a VAMA increased the risk of preterm labor by 1.2 (95\% CI $1.06 \pm 1.36)$ as compared to pregnancy at 30-34 years of age, even after adjusting for confounding variables. Beyond that, they found the distribution of preterm labor according to the age group to be a "U" shaped distribution; thus, not only is AMA a risk factor for preterm labor, but young maternal age is a risk factor as well. ${ }^{53}$

The mechanism which explains the association between maternal age and preterm birth is not entirely clear. There are several possible factors: placental pathology, which may also contribute to the increased incidence of preeclampsia in AMA. This also constitutes an iatrogenic factor of preterm induction of labor. ${ }^{54}$ Progesterone deficiency is another possible explanation. It is well established that progesterone is important for maintaining a pregnancy. ${ }^{55}$ This is a possible mechanism since progesterone levels decline with increasing age.

\section{Small for Gestational Age Infants and Growth Restriction}

The relationship between SGA and maternal age is believed to be a positive dose-response relationship.

Kenny and her colleagues performed a populationbased cohort study in the UK, and they demonstrated that AMA was not associated with increased risk of SGA after adjustment for significant cofactors. ${ }^{56}$ Similar findings were also reported by Kozuki et al in a metaanalysis. ${ }^{57}$ On the contrary, Khalil et al reported a higher risk for SGA among women with VAMA (OR 1.46, 95\% CI 1.27-1.69). ${ }^{18}$ In addition, Lean et al in a large recent systematic review and meta-analysis reported higher rates of SGA (birth weight below 10th percentile) infants among women with AMA (OR 1.16, 95\% CI 1.06-1.27). This association was significant only among VAMA (OR, 95\% CI 1.20 (1.07-1.33)) and EAMA (OR, 95\% CI 1.57 (1.17-2.10)) but not among AMA women (OR 1.22, 95\% CI 0.86-1.73). The authors also found an increased risk of fetal growth restriction (FGR), defined by the authors as birth weight below 5th percentile, with OR 1.23 (95\% CI 1.01-1.52) while among women above 40 years old the risk increases 1.53 fold (95\% CI 1.07-2.20). ${ }^{58}$ Moreover, another systematic review of maternal and neonatal outcomes in women with EAMA found that women in an EAMA had a 1.92 greater likelihood of an IUGR during pregnancy. ${ }^{34}$ Odibo et al also identified a positive doseresponse relationship between advanced maternal age and increased risk of FGR. ${ }^{59}$ Although the exact mechanism of the association between advanced maternal age and SGA has not been demonstrated, it has been suggested that poor oxygen exchange may be the underlying factor. ${ }^{60}$

\section{Intrauterine Fetal Death and Stillbirth}

Intrauterine Fetal Death (IUFD) or stillbirth is defined as fetal death after 20 weeks of gestation. The association between AMA and stillbirth is not clear. Salihu et al, in a retrospective cohort study, demonstrated a two-fold increase in stillbirth (95\% CI 1.7-2.4) in AMA and 3.4 fold increase (95\% CI 2.8-4.2) in VAMA, where women aged 20-24 years old were the referent category. ${ }^{61}$ Likewise, a large meta-analysis of 44 studies, including 44,723,207 births, of which 185,384 were stillborn, found an increased risk of IUFD at AMA (OR 1.75, 95\% CI $1.62-1.89)$. They hypothesized that the increased rate of stillbirth was related to placental aging, as a result of vascular dysfunction due to advanced age. ${ }^{58}$ 
On the contrary, a large cohort study, of 369,516 singleton pregnancies in Denmark, compared the incidence of IUFD between AMA, VAMA, and a control group of women aged 20-34 years old. The risk of stillbirth was higher for AMA $(0.35 \%$ vs $0.28 \%$, aOR 1.43 [99.8\% CI $1.05-1.96])$ but with no statistical significance in the VAMA group $(0.43 \%$ vs $0.28 \%$, OR 1.47 [99.8\% CI $0.76-2.84]){ }^{8}$

In conclusion, there is an increased risk for IUFD in AMA, but there seems to be a modest increase in incidence, particularly in developed countries. Given that induction of labor at 39 weeks is considered a safe procedure with a low rate of adverse outcomes, it is reasonable to offer induction of labor at term pregnancy to AMA women, to reduce the stillbirth rate. ${ }^{27,62}$

\section{Apgar Scores and NICU Admissions}

Most of the studies did not find low Apgar scores among women with AMA.

Yogev et al reported similar rates of low Apgar score (5 $\min ,<7)$ among the different age groups. ${ }^{63}$ In a crosssectional study from Japan, the authors did not find a difference in low Apgar scores (5 min, <7) among women with AMA, VAMA, and EAMA (multivariate RR $1.02,(0.97-1.07), 1.06(0.98-1.15)$ and $1.03(0.68-1.56)$, respectively). ${ }^{64}$ Similarly, Kahveci et al examined the impact of advanced maternal age on perinatal and neonatal outcomes of nulliparous singleton pregnancies in Turkey and found no significant differences regarding Apgar scores among women with AMA and VAMA. However, the admission to the NICU was more frequent in the AMA and VAMA groups; aOR1.68 (95\% CI 1.42-2.15, P < $0.01)$ and aOR $1.52(95 \% \mathrm{CI}, 1.21-1.92, \mathrm{P}<0.01)$ in the AMA and VAMA groups, respectively. ${ }^{60}$

Another systematic review of the maternal and neonatal outcomes of women with EAMA reported that women of EAMA had a 2.49 (1.37-4.54) risk of an abnormal 5-minute Apgar score. ${ }^{34}$

\section{Autism Spectrum Disorder}

Both advanced maternal and paternal age are risk factors for autism in offspring.

A large meta-analysis, including 16 epidemiological papers with 5687 autism spectrum disorder (ASD) cases and 8,655,576 control subjects, was conducted. Almost all studies demonstrated a dose-response effect of maternal age on the risk of autism. The meta-regression suggested a stronger maternal age effect in studies with more male offspring and for children diagnosed in later years. ${ }^{65}$

Possible biological mechanisms include de novo aberration and mutations, or epigenetic alterations associated with aging.

\section{Conclusion and Recommendations Pre-Conception Counseling}

Women at an AMA should be encouraged to optimize their health when preparing for pregnancy; stop smoking and drinking alcohol, start physical activity, achieve normal body weight, take folic acid supplements and stabilize comorbidities.

\section{Low-Dose Aspirin Prophylaxis}

According to the criteria for risk factor preeclampsia of the United States Preventive Services Task Force (USPSTF) high-risk criteria, and endorsed by the American College of Obstetricians and Gynecologists (ACOG),${ }^{66,67}$ AMA is considered a moderate risk factor. Thus, low-dose aspirin prophylaxis is recommended only when another moderate risk factor (nulliparity, obesity, family history of preeclampsia in mother or sister, African American race, low socioeconomic status, previous pregnancy with SGA infant, stillbirth or interval $>10$ years between pregnancies) exists or in the presence of other high-risk factors.

\section{Invasive Diagnostic Procedures}

AMA itself should not be considered an indication for invasive diagnostic procedures. It is often funded by the health authorities. AMA women should be encouraged and counseled to perform the aneuploidy screening tests (preferably the cfDNA testing) along with a detailed ultrasound. AMA women should be informed of the relatively high safety of amniocentesis.

\section{PGT-A}

More research is needed regarding the benefit of PGT-A in reducing miscarriage rates.

\section{Induction of Labor}

Given the increased risk for stillbirth women of AMA, and particularly in VAMA, it is reasonable to offer them induction of labor or elective $\mathrm{CD}$ at 39 weeks gestation. ${ }^{68}$ 


\section{Author Contributions}

All authors made a significant contribution to the work reported, whether that is in the conception, study design, execution, acquisition of data, analysis and interpretation, or in all these areas; took part in drafting, revising or critically reviewing the article; gave final approval of the version to be published; have agreed on the journal to which the article has been submitted; and agree to be accountable for all aspects of the work.

\section{Funding}

This review did not receive any specific grant from funding agencies in the public, commercial, or not-for-profit sectors.

\section{Disclosure}

The authors report no conflicts of interest for this work.

\section{References}

1. United Nations Population Division D of E and SA. World fertility patterns 2015-data booklet (ST/ESA/SER. A/370); 2015.

2. Martin JA, Hamilton BE, Ventura SJ, Osterman MJK, Wilson EC, Mathews TJ. Births: final data for 2010. Natl Vital Stat Reports from Centers Dis Control Prev Natl Cent Heal Stat Natl Vital Stat Syst. 2012;61(1):1-72.

3. Hamilton BE, Martin JA, Osterman MJK. Births: provisional data for 2019. NVSS Vital Stat Rapid Release. 2020;8:1-10.

4. Guedes M, Canavarro MC. Characteristics of primiparous women of advanced age and their partners: a homogenous or heterogenous group? Birth. 2014;41(1):46-55. doi:10.1111/birt.12089

5. Bayrampour H, Heaman M. Comparison of demographic and obstetric characteristics of Canadian primiparous women of advanced maternal age and younger age. JOGC. 2011;33(8):820-829. doi:10.1016/S1701-2163(16)34985-4

6. Sauer MV. Reproduction at an advanced maternal age and maternal health. Fertil Steril. 2015;103(5):1136-1143. doi:10.1016/j. fertnstert.2015.03.004

7. Kawwass JF, Badell ML. Maternal and fetal risk associated with assisted reproductive technology. Obstet Gynecol. 2018;132 (3):763-772. doi:10.1097/AOG.0000000000002786

8. Frederiksen LE, Ernst A, Brix N, et al. Risk of adverse pregnancy outcomes at advanced maternal age. Obstet Gynecol. 2018;131 (3):457-463. doi:10.1097/AOG.0000000000002504

9. Pinheiro RL, Areia AL, Mota Pinto A, Donato H. Advanced maternal age: adverse outcomes of pregnancy, a meta-analysis. Acta Med Port. 2019;32(3):219-226. doi:10.20344/amp.11057

10. Kanmaz AG, Inan AH, Beyan E, Ögür S, Budak A. Effect of advanced maternal age on pregnancy outcomes: a single-centre data from a tertiary healthcare hospital. J Obstet Gynaecol J Inst Obstet Gynaecol. 2019;39 (8):1104-1111. doi:10.1080/01443615.2019.1606172

11. Claramonte Nieto M, Meler Barrabes E, Garcia Martínez S, Gutiérrez Prat M, Serra Zantop B. Impact of aging on obstetric outcomes: defining advanced maternal age in Barcelona. BMC Pregnancy Childbirth. 2019;19(1):342. doi:10.1186/s12884-019-2415-3

12. Storeide O, Veholmen M, Eide M, Bergsjø P, Sandvei R. The incidence of ectopic pregnancy in Hordaland County, Norway 19761993. Acta Obstet Gynecol Scand. 1997;76(4):345-349. doi:10.1111/j.1600-0412.1997.tb07990.x
13. Nybo Andersen AM, Wohlfahrt J, Christens P, Olsen J, Melbye M. Maternal age and fetal loss: population based register linkage study. BMJ. 2000;320(7251):1708-1712. doi:10.1136/bmj.320.7251.1708

14. Attali E, Yogev Y. The impact of advanced maternal age on pregnancy outcome. Best Pract Res Clin Obstet Gynaecol. 2021;70:2-9. doi:10.1016/j.bpobgyn.2020.06.006

15. Savage PM, Sita-Lumsden A, Dickson S, et al. The relationship of maternal age to molar pregnancy incidence, risks for chemotherapy and subsequent pregnancy outcome. J Obstet Gynaecol J Inst Obstet Gynaecol. 2013;33(4):406-411. doi:10.3109/01443615.2013.771159

16. Gockley AA, Melamed A, Joseph NT, et al. The effect of adolescence and advanced maternal age on the incidence of complete and partial molar pregnancy. Gynecol Oncol. 2016;140(3):470-473. doi:10.1016/j.ygyno.2016.01.005

17. Zipori Y, Linder R, Khatib N, Weiner Z, Barzilay E. Advanced maternal age and perinatal outcome in twin pregnancies: a meta-analysis. J Matern Neonatal Med off J Eur Assoc Perinat Med Fed Asia Ocean Perinat Soc Int Soc Perinat Obstet. 2020;33 (18):3193-3199. doi:10.1080/14767058.2019.1570112

18. Khalil A, Syngelaki A, Maiz N, Zinevich Y, Nicolaides KH. Maternal age and adverse pregnancy outcome: a cohort study. Ultrasound Obstet Gynecol. 2013;42(6):634-643. doi:10.1002/uog.12494

19. Fitzpatrick KE, Tuffnell D, Kurinczuk JJ, Knight M. Pregnancy at very advanced maternal age: a UK population-based cohort study. BJOG. 2017;124(7):1097-1106. doi:10.1111/1471-0528.14269

20. Dong B, Yu H, Wei Q, et al. The effect of pre-pregnancy body mass index and excessive gestational weight gain on the risk of gestational diabetes in advanced maternal age. Oncotarget. 2017;8 (35):58364-58371. doi:10.18632/oncotarget.17651

21. Sheen -J-J, Wright JD, Goffman D, et al. Maternal age and risk for adverse outcomes. Am J Obstet Gynecol. 2018;219(4):390.e1-390. e15. doi:10.1016/j.ajog.2018.08.034

22. Bartsch E, Medcalf KE, Park AL, Ray JG. Clinical risk factors for pre-eclampsia determined in early pregnancy: systematic review and meta-analysis of large cohort studies. BMJ. 2016;353:11753. doi:10.1136/bmj.i1753

23. Tyas BD, Lestari P, Aldika Akbar MI. Maternal perinatal outcomes related to advanced maternal age in preeclampsia pregnant women. J Fam Reprod Heal. 2019;13(4):191-200.

24. Wu P, Haththotuwa R, Kwok CS, et al. Preeclampsia and future cardiovascular health: a systematic review and meta-analysis. Circ Cardiovasc Qual Outcomes. 2017;10(2):e003497. doi:10.1161/ CIRCOUTCOMES.116.003497

25. Tessema GA, Tekeste A, Ayele TA. Preeclampsia and associated factors among pregnant women attending antenatal care in Dessie referral hospital, Northeast Ethiopia: a hospital-based study. $B M C$ Pregnancy Childbirth. 2015;15(1):73. doi:10.1186/s12884-0150502-7

26. Lamminpää R, Vehviläinen-Julkunen K, Gissler M, Heinonen S. Preeclampsia complicated by advanced maternal age: a registrybased study on primiparous women in Finland 1997-2008. BMC Pregnancy Childbirth. 2012;12:47. doi:10.1186/1471-2393-12-47

27. Frick AP. Advanced maternal age and adverse pregnancy outcomes. Best Pract Res Clin Obstet Gynaecol. 2021;70:92-100. doi:10.1016/j. bpobgyn.2020.07.005

28. Richards MK, Flanagan MR, Littman AJ, Burke AK, Callegari LS. Primary cesarean section and adverse delivery outcomes among women of very advanced maternal age. J Perinatol. 2016;36 (4):272-277. doi:10.1038/jp.2015.204

29. Treacy A, Robson M, O'Herlihy C. Dystocia increases with advancing maternal age. Am J Obstet Gynecol. 2006;195(3):760-763. doi:10.1016/j.ajog.2006.05.052

30. Waldenström U, Ekéus C. Risk of labor dystocia increases with maternal age irrespective of parity: a population-based register study. Acta Obstet Gynecol Scand. 2017;96(9):1063-1069. doi:10.1111/aogs.13167 
31. Rydahl E, Declercq E, Juhl M, Maimburg RD. Cesarean section on a rise-Does advanced maternal age explain the increase? A population register-based study. PLoS One. 2019;14(1):e0210655. doi:10.1371/ journal.pone. 0210655

32. Correa-de-araujo R, Yoon SSS. Clinical outcomes in high-risk pregnancies due to advanced maternal age. $J$ Womens Health (Larchmt). 2021;30(2):160-167. doi:10.1089/jwh.2020.8860

33. Heffner LJ. Advanced maternal age-how old is too old? $N$ Engl J Med. 2004;351(19):1927-1929. doi:10.1056/NEJMp048087

34. Leader J, Bajwa A, Lanes A, et al. The effect of very advanced maternal age on maternal and neonatal outcomes: a systematic review. JOGC. 2018;40(9):1208-1218. doi:10.1016/j.jogc.20 17.10.027

35. Petracchi F, Colaci DS, Igarzabal L, Gadow E. Cytogenetic analysis of first trimester pregnancy loss. Int $J$ Gynaecol Obstet off Organ Int Fed Gynaecol Obstet. 2009;104(3):243-244. doi:10.1016/j. ijgo.2008.10.014

36. Spandorfer SD, Davis OK, Barmat LI, Chung PH, Rosenwaks Z. Relationship between maternal age and aneuploidy in in vitro fertilization pregnancy loss. Fertil Steril. 2004;81(5):1265-1269. doi:10.1016/j.fertnstert.2003.09.057

37. Dai R, Li L, Zhu H, Geng D, Deng S, Liu R. Effect of maternal age on spontaneous abortion during the first trimester in Northeast China. J Matern Neonatal Med off J Eur Assoc Perinat Med Fed Asia Ocean Perinat Soc Int Soc Perinat Obstet. 2018;31(14):1824-1829. doi:10.1080/14767058.2017.1330330

38. Mikwar M, MacFarlane AJ, Marchetti F. Mechanisms of oocyte aneuploidy associated with advanced maternal age. Mutat Res. 2020;785:108320. doi:10.1016/j.mrrev.2020.108320

39. Rubio C, Bellver J, Rodrigo L, et al. In vitro fertilization with preimplantation genetic diagnosis for aneuploidies in advanced maternal age: a randomized, controlled study. Fertil Steril. 2017;107(5):1122-1129. doi:10.1016/j.fertnstert.2017.03.011

40. Sacchi L, Albani E, Cesana A, et al. Preimplantation genetic testing for aneuploidy improves clinical, gestational, and neonatal outcomes in advanced maternal age patients without compromising cumulative live-birth rate. J Assist Reprod Genet. 2019;36(12):2493-2504. doi:10.1007/s10815-019-01609-4

41. Penzias A, Bendikson K, Butts S. The use of preimplantation genetic testing for aneuploidy (PGT-A): a committee opinion. Fertil Steril. 2018;109(3):429-436. doi:10.1016/j.fertnstert.2018.01.002

42. Kim YJ, Lee JE, Kim SH, Shim SS, Cha DH. Maternal age-specific rates of fetal chromosomal abnormalities in Korean pregnant women of advanced maternal age. Obstet Gynecol Sci. 2013;56(3):160-166. doi:10.5468/ogs.2013.56.3.160

43. Carothers AD, Frackiewicz A, De Mey R, et al. A collaborative study of the aetiology of turner syndrome. Ann Hum Genet. 1980;43 (4):355-368. doi:10.1111/j.1469-1809.1980.tb01570.x

44. Forabosco A, Percesepe A, Santucci S. Incidence of non-agedependent chromosomal abnormalities: a population-based study on 88965 amniocenteses. Eur J Hum Genet. 2009;17(7):897-903. doi:10.1038/ejhg.2008.265

45. Hagman A, Wennerholm U-B, Källén K, et al. Women who gave birth to girls with turner syndrome: maternal and neonatal characteristics. Hum Reprod. 2010;25(6):1553-1560. doi:10.1093/ humrep/deq060

46. Kagan KO, Sroka F, Sonek J, et al. First-trimester risk assessment based on ultrasound and cell-free DNA vs combined screening: a randomized controlled trial. Ultrasound Obstet Gynecol off $J$ Int Soc Ultrasound Obstet Gynecol. 2018;51(4):437-444. doi:10.1002/uog.18905

47. Grinshpun-Cohen J, Miron-Shatz T, Berkenstet M, Pras E. The limited effect of information on Israeli pregnant women at advanced maternal age who decide to undergo amniocentesis. ISR $J$ Health Policy Res. 2015;4:23. doi:10.1186/s13584-015-0019-6
48. Grinshpun-Cohen J, Miron-Shatz T, Ries-Levavi L, Pras E. Factors that affect the decision to undergo amniocentesis in women with normal down syndrome screening results: it is all about the age. Heal Expect Int J Public Particip Heal Care Heal Policy. 2015;18 (6):2306-2317. doi:10.1111/hex.12200

49. Dommergues M, Audibert F, Benattar C, Champagne C, Gomel V, Frydman R. Is routine amniocentesis for advanced maternal age still indicated? Fetal Diagn Ther. 2001;16(6):372-377. doi:10.1159/ 000053943

50. Salomon LJ, Sotiriadis A, Wulff CB, Odibo A, Akolekar R. Risk of miscarriage following amniocentesis or chorionic villus sampling: systematic review of literature and updated meta-analysis. Ultrasound Obstet Gynecol off J Int Soc Ultrasound Obstet Gynecol. 2019;54(4):442-451. doi:10.1002/uog.20353

51. Goetzinger KR, Shanks AL, Odibo AO, Macones GA, Cahill AG. Advanced maternal age and the risk of major congenital anomalies. Am J Perinatol. 2017;34(3):217-222. doi:10.1055/s-0036-1585410

52. Waldenström U, Cnattingius S, Vixner L, Norman M. Advanced maternal age increases the risk of very preterm birth, irrespective of parity: a population-based register study. BJOG. 2017;124 (8):1235-1244. doi:10.1111/1471-0528.14368

53. Fuchs F, Monet B, Ducruet T, Chaillet N, Audibert F. Effect of maternal age on the risk of preterm birth: a large cohort study. PLoS One. 2018;13(1):e0191002. doi:10.1371/journal.pone.0191002

54. Scime NV, Chaput KH, Faris PD, Quan H, Tough SC, Metcalfe A. Pregnancy complications and risk of preterm birth according to maternal age: a population-based study of delivery hospitalizations in Alberta. Acta Obstet Gynecol Scand. 2020;99(4):459-468. doi:10.1111/aogs.13769

55. Mesiano S. Roles of estrogen and progesterone in human parturition. Front Horm Res. 2001;27:86-104. doi:10.1159/000061038

56. Kenny LC, Lavender T, McNamee R, O’Neill SM, Mills T, Khashan AS. Advanced maternal age and adverse pregnancy outcome: evidence from a large contemporary cohort. PLoS One. 2013;8 (2):e56583. doi:10.1371/journal.pone. 0056583

57. Kozuki N, Lee ACC, Silveira MF, et al. The associations of parity and maternal age with small-for-gestational-age, preterm, and neonatal and infant mortality: a meta-analysis. BMC Public Health. 2013;13 Suppl 3(Supp13):S2. doi:10.1186/1471-2458-13-S3-S2

58. Lean SC, Derricott H, Jones RL, Heazell AEP. Advanced maternal age and adverse pregnancy outcomes: a systematic review and meta-analysis. PLoS One. 2017;12(10):e0186287. doi:10.1371/journal.pone. 0186287

59. Odibo AO, Nelson D, Stamilio DM, Sehdev HM, Macones GA. Advanced maternal age is an independent risk factor for intrauterine growth restriction. Am J Perinatol. 2006;23(5):325-328. doi:10.1055/ s-2006-947164

60. Kahveci B, Melekoglu R, Evruke IC, Cetin C. The effect of advanced maternal age on perinatal outcomes in nulliparous singleton pregnancies. BMC Pregnancy Childbirth. 2018;18(1):343. doi:10.1186/s12884-018-1984-x

61. Salihu HM, Wilson RE, Alio AP, Kirby RS. Advanced maternal age and risk of antepartum and intrapartum stillbirth. $J$ Obstet Gynaecol Res. 2008;34(5):843-850. doi:10.1111/j.1447-0756.2008.00855.x

62. Grobman WA, Rice MM, Reddy UM, et al. Labor induction versus expectant management in low-risk nulliparous women. $N$ Engl $J$ Med. 2018;379(6):513-523. doi:10.1056/NEJMoa1800566

63. Yogev Y, Melamed N, Bardin R, Tenenbaum-Gavish K, Ben-Shitrit G, Ben-Haroush A. Pregnancy outcome at extremely advanced maternal age. Am J Obstet Gynecol. 2010;203(6):558.e1-7. doi:10.1016/j.ajog.2010.07.039

64. Ogawa K, Urayama KY, Tanigaki S, et al. Association between very advanced maternal age and adverse pregnancy outcomes: a cross sectional Japanese study. BMC Pregnancy Childbirth. 2017;17 (1):349. doi:10.1186/s12884-017-1540-0 
65. Sandin S, Hultman CM, Kolevzon A, Gross R, MacCabe JH, Reichenberg A. Advancing maternal age is associated with increasing risk for autism: a review and meta-analysis. $\mathrm{J} \mathrm{Am} \mathrm{Acad} \mathrm{Child} \mathrm{Adolesc}$ Psychiatry. 2012;51(5):477-486.e1. doi:10.1016/j.jaac.2012.02.018

66. LeFevre ML. Low-dose aspirin use for the prevention of morbidity and mortality from preeclampsia: U.S. preventive services task force recommendation statement. Ann Intern Med. 2014;161(11):819-826. doi:10.7326/M14-1884
67. American College of Obstetricians and Gynecologists. ACOG committee opinion No. 743: low-dose aspirin use during pregnancy. Obstet Gynecol. 2018;132(1):e44-e52. doi:10.1097/AOG.000000000 0002708

68. Impact S, No P. Induction of labour at term in older mothers. $R$ Coll Obstet Gynaecol -Scientific Impact Pap. 2013;34.

\section{Publish your work in this journal}

The International Journal of Women's Health is an international, peerreviewed open-access journal publishing original research, reports, editorials, reviews and commentaries on all aspects of women's healthcare including gynecology, obstetrics, and breast cancer. The manuscript management system is completely online and includes a very quick and fair peer-review system, which is all easy to use. Visit http://www.dovepress.com/testimonials.php to read real quotes from published authors. 